\title{
COMPETITION ASSESSMENT IN BUSINESS NEGOTIATIONS UNDER DISTORTING MARKET CONDITIONS
}

\author{
Kęstutis Peleckis ${ }^{1}$, Valentina Peleckienè ${ }^{2}$, Bahman Peyravi ${ }^{3}$, Edita Leonavičiené $\dot{4}^{4}$ \\ ${ }^{1}$ Department of Economics Engineering, Faculty of Business Management, \\ Vilnius Gediminas Technical University, Sauletekio al. 11, LT-10223 Vilnius, Lithuania \\ ${ }^{2,3}$ Department of Management, Faculty of Business Management, \\ Vilnius Gediminas Technical University, Sauletekio al. 11, LT-10223 Vilnius, Lithuania \\ ${ }^{4}$ Department of Business Technologies and Entrepreneurship, Faculty of Business Management, \\ Vilnius Gediminas Technical University, Sauletekio al. 11, LT-10223 Vilnius, Lithuania \\ E-mails: ${ }^{1}$ k.peleckis@vgtu.lt (corresponding author); ${ }^{2}$ valentina.peleckiene@vgtu.lt; \\ ${ }^{3}$ bahman.peyravi@vgtu.lt; ${ }^{4}$ edita.leonaviciene@vgtu.lt
}

Received 28 February 2020; accepted 05 May 2020

\begin{abstract}
The competition assessment process provides an analytical framework for business negotiation entities to mitigate, or avoid potential competition problems. It helps to identify possible alternatives that may reduce, or eliminate potential harm to competition. Limiting the number of business negotiation entities leads to the risk that market power will be created and competitive rivalry will be reduced. The aim of the article is to analyze the theory and practice of developing and implementing business negotiation strategies in a complex way, also to evaluate the level of competition in distorting market conditions. The object of the study is to strike a balance at the level of competition in business negotiations, under distorting market conditions. The scientific problem is that bargaining theory lacks tools to assess and balance the level of competition between participants in market conditions that distort competition.
\end{abstract}

Keywords: competition, negotiations, competition assessment, market structure, market regulation, market power.

JEL Classification: D4, D9, F51.

\section{Introduction}

The activities of national competition authorities include, for example, attempts by entrepreneurs and professional organizations to identify barriers of entry to markets, increase costs for corporate competitors and coordinate (as opposed to competition) the competitors' pricing and production strategies. Because of reduced competition some kind of business is out of control, so this can lead to higher prices for consumers, loss of product variety and quality, loss of innovation, and loss of business bargaining power. The knowledge of the concepts and fundamentals of competition are useful for a broader understanding of the impact of regulations or government policy interventions. If we look at the history of rules and regulations adopted by governments and restrictions imposed by professional organizations, they often restrict access to markets and create various distortions that lead to inefficient market outcomes.

The rules and regulations are designed to meet a variety of socio-economic objectives pursued by governments and can:
- identify barriers to competition, such as restrictions on access or flow of goods and services within regions;

- facilitate price and production coordination between competitors.

- higher costs for participants and small businesses compared to incumbents or larger companies,

- protects companies partially or completely from national competition laws.

One type of business conduct that is most harmful to competition is the formation of cartels (Niu, Dong, \& Chen, 2012; OECD, 2017a, 2017b, 2017c; Phillips \& Menkhaus, 2010; Pinto \& Falcão-Reis, 2019; Ren \& Zhang, 2014; Ritter et al., 2019; Willems \& De Corte, 2008; Yang, Zhang, \& Gao, 2019).

Because of cartels, of covert or concerted conduct are rising prices, declining quantities of goods, potentially less their variety and innovations, there is an obvious loss of well-being, also limits the bargaining power of negotiating parties. Today collusion is illegal in most countries. For example, in some industries, companies are work- 
ing together to set standards and compatibility rules, also by conducting research and development (R\&D). For some professions and manufacturers of goods and services historically, the opportunity has been afforded to engage in selfregulation (or co-regulation) in areas such as product properties, including quality and safety, coordination of technical standards, ethical standards of professional practice, and pollution control. Of course, giving priority to certain types of cooperation can bring significant benefits as it can lead to more efficient market outcomes and reduce the need for more formal regulation.

The aim of this article is to analyze in complex the unfolding theory and practice of development and implementation of business negotiating strategies, assessing competition level under distorting market conditions, to reveal opportunities on development and implementing improvements of these strategies. Object of the research is the search of balance on competition level in business negotiations under distorting market conditions.

The scientific problem - negotiation theory lacks measures for assessment and balancing the competition level of negotiation's participants under distorting market conditions.

Research methods - scientific literature analysis, comparative, logical analysis and synthesis, comparative and generalisation methods.

\section{Impact of cost asymmetry on the competi- tiveness of business entities}

Occasionally, due to legislation, some suppliers increase their prices compared to their competitors in the negotiations. One source of cost asymmetry is due to the rule that unnecessarily requires the use of one production technology over another. Another source is the "propogation of old players", which exempts incumbent suppliers from the regulation but applies to new entrants. The source is and grants or preferential financing to state-owned or preferred companies. Such agreements have great potential to distort bargaining competitive relationships in the industry having a greater impact on the costs of some suppliers than others (Maravillo et al., 2019; Motalleb, Annaswamy, \& Ghorbani, 2018; Moye-Holz, van Dijk, Reijneveld, \& Hogerzeil, 2019; Murto et al., 2019; Niu et al., 2012; OECD, 2017a, 2017b, 2017c; Phillips \& Menkhaus, 2010; Pinto \& Falcão-Reis, 2019; Ren \& Zhang, 2014; Ritter et al., 2019; Willems \& De Corte, 2008; Yang et al., 2019). This can create inefficiencies, hamper market entry, reduce corporate-led innovation and reduce the intensity of competitive bargaining in the market, affecting the balance of bargaining power. Although creating cost differences can be detrimental, this does not mean that in regulations should always be pursued equal supplier prices.

A regulation requiring registration of certain professional experience may include derogations from the old participants allowing those, with extensive professional experience to register, even if they have no training or qualifications, which are needed to register in new applications. When it comes to productive technology, these reservations are often enforced to ensure that would be enough time for previous investments to amortize hidden costs. The anti-competitive effects of grandparent clauses can be mitigated by ensuring that they would be limited in time, not permanent. Duration of the exception should in particular be strictly proportionate to the reservation, which it seeks to justify. Overall, though should be taken a skeptical approach to arguments due to the need for grandparents' clauses, as they often reflect attempts to protect interests from potential competition.

Subsidies can be useful in many cases, but when they fundamentally change the competitive conditions of the negotiations by favoring inefficient companies, they can push business towards less efficient providers. Alternatives to subsidies may include restructuring in order to eliminate uneconomic activities and make business more productive, although special subsidies may sometimes be needed to support such a transformation. In some jurisdictions, subsidies are limited to ensure that they are not constant, that they are indeed aimed at improving the performance of promising firms and eliminating market failures and that their negative impact on competition in the negotiations remains limited. Regulations can influence the behavior of suppliers not only by changing their ability to compete in the negotiations, but also by changing the incentive to act as vigorous competitors. The main reasons why suppliers may be less competitive in negotiations are due to regulations that may facilitate coordination between themselves or reduce customer willingness, ability or incentive to switch to different suppliers (Cogley et al., 2018; Borne et al., 2018; Brooks \& Lesieutre, 2019; Cimon \& Garriott, 2019; Croutzet \& Lasserre, 2017; D'Aertrycke, Ehrenmann, \& Smeers, 2017). Other reasons include profit or market share thresholds that limit potential returns on competition. Cartel behavior can occur more easily in self-regulation or co-regulation mode increasing the output and price information of some suppliers or eliminating the industry or branch 
from the competition law. A cartel exists when competitors agree to restrict competition in negotiations, for example by fixing prices, restricting supply, sharing profits or competing, thereby increasing their overall profits. Cartels are harmful because they limit output and raise prices, harming the consumers. The risk of cartel activities must be balanced with the potential benefits of selfregulation as faster certification of new technologies. When an industry or professional association assumes full responsibility for regulating the behavior of its members without government backing (often requiring the government), the term "selfregulation" is used. However, when the government provides legislative rules that are at least partially created by industry / professional associations, the term "common regulation" is used. Selfregulation and common regulation structures can bring significant benefits by ensuring that technical standards are appropriate and that standards are improving along with technology. However, these structures may have significant anti-competitive effects (D'Aertrycke et al., 2017; Denis, 2012; Gissey, Dodds, \& Radcliffe, 2018; Hu et al., 2018; Lee et al., 2018; Lohmann \& Trischler, 2017). In particular, industrial and professional associations often adopt rules that reduce incentives or opportunities for active competition between suppliers of goods or services, such as advertising restrictions and rules that prevent discounts. By the way, requirements which are unreasonably strict for qualification, can reduce entry to the market. Governments should keep up powers to prevent associations of industry/professionals attempts to exercise regulatory powers in an anti-competitive way. This may include either by ensuring that selfregulation or common regulation, of course continues to be subject to competition law enforcement or that the relevant governmental authorities are entitled to approve or refuse the association's rules and, if necessary, change its rules if the association continues to propose unacceptable rules. Regulations requiring market participants to publish information on their prices or output levels can make a significant contribution to the formation of cartels, since the basic requirement for the functioning of a cartel is that participants can effectively monitor their competitors (or other conspirator's) market behavior.

Cartels and implicit coordination are more likely when (Cimon \& Garriott, 2019; Croutzet \& Lasserre, 2017; D’Aertrycke et al., 2017; Denis, 2012; Gissey et al., 2018; Hu et al., 2018; Lee et al., 2018; Lohmann \& Trischler, 2017): there are fewer players in the market; entry barriers are high; supplier products are relatively homogeneous; and information is available before or shortly after the change occurs in prices or output. May be accepted regulations requiring the publication of information such as price and output levels to improve consumer information and sometimes it can improve the efficiency of markets. However, as the cartel develops, such requirements are likely to have a more negative effect. There are other options where it is not necessary to publish all the data collected.

When information is primarily collected for government policy making, it may not be necessary to publish it. When the goal is to help users or provide general statistics, the general statistics supports cartels less than company-specific statistics, and historical statistics are less supportive than current information. General corporate statistics discourage cartel members from identifying suppliers infringing the cartel agreement, meanwhile company-specific statistics can clearly identify the company, which departed from the cartel agreement because of price or quantity. As cartels have to share the newest information to distribute output and set target prices, historical statistics and information are less useful to them (Niu et al., 2012; OECD, 2017a, 2017b, 2017c; Phillips \& Menkhaus, 2010; Pinto \& Falcão-Reis, 2019; Ren \& Zhang, 2014; Ritter et al., 2019; Willems \& De Corte, 2008; Yang et al., 2019).

\section{Exceptions to competition}

In many countries, specific suppliers or sectors of the economy enjoy exceptions to general competition law, but some sectors are subject to sectorspecific competition laws (Borne et al., 2018; Brooks \& Lesieutre, 2019; Cimon \& Garriott, 2019; Croutzet \& Lasserre 2017; D'Aertrycke et al., 2017; Denis, 2012; Gissey et al., 2018; Hu et al., 2018; Lee et al., 2018; Lohmann \& Trischler, 2017).

In other cases, there is no restriction on anticompetitive behavior. If there is the essential exception from the general application of competition law there are obvious risks of cartel abusive prices and anti-competitive mergers.

A merger is a combination of two (or more) previously independent firms in order to be formed one larger company. When it is concrete basis for further application exception should be considered how to minimize its impact. For example, a statutory monopoly requiring all manufacturers to sell certain goods for a licensed wholesaler may be more restrictive than allowing manufacturers to sell by agreement. 


\subsection{Customer mobility}

Legislation may make consumers more or less willing to switch suppliers, affecting the "switching costs" - the explicit and implicit costs for a consumer switching from one supplier to another (Brooks \& Lesieutre, 2019; Cimon \& Garriott, 2019; Croutzet \& Lasserre, 2017). Replacement costs can occur for a variety of reasons, including lengthy contract terms or tying assets with suppliers in a way that is inconvenient, for example, by associating a phone number with a particular service provider. When consumers have high switching costs, suppliers may charge higher prices for their goods or services and will sometimes promote policies that aim to ensure high replacement costs. Enhancing competition in negotiations, reduction or elimination of replacement costs can be large, so policymakers should avoid policies that increase the cost of replacement for consumers. Where there is a clear risk that replacement costs will be determined, provisions should be included in the regulatory framework to restrict or prohibit their use.

It should be properly taken into account the legitimate consumer replacement costs. Even if the supplier incurs significant costs due to the switching process, provided that the pro-competitive effects of the cost reduction or elimination are significant, the regulatory authority may want to prevent suppliers clearly to recover these costs from consumers. Business competition before a buyer makes a purchase decision can help reduce the negative impact of replacement costs.

\subsection{Competition policy}

An important reason for market reforms is that governments clearly understand the benefits of competition. In many unregulated industries such as telecommunications, electricity and airlines, one of the alleged competitive advantages was overcapacity, resulting from regulation, which would ultimately lead to a reduction in efficiency, which would increase production efficiency and reduce prices for consumers. Cogley et al. (2018) emphasizes that as many industries are privatized or liberalized worldwide, governments clearly understand the competitive advantages.

Business competition can help improve manufacturing efficiency and provide consumers with newer and better products through innovations, which can boost economic growth and consumer welfare (Croutzet \& Lasserre, 2017; D'Aertrycke et al., 2017; Denis, 2012; Gissey et al., 2018; Hu et al., 2018; Lee et al., 2018; Niu et al., 2012; OECD, 2017a, 2017b, 2017c). In general, competi- tion between suppliers usually results in lower prices and greater choice. To understand how these benefits directly benefit consumers, there are some examples which illustrate the overall benefits of competition without necessarily focusing on regulatory constraints. Customers benefit by being able to choose between different providers, and so does the economy as a whole. Their options to choose are forcing firms to compete with each other. Customer choice is a good thing, but competition between firms also leads to increased productivity and economic growth. It may be difficult to measure the direct impact of, for example, competition law on economic growth. However, there is strong evidence that supports each of the links below.

Most importantly, it is clear that industries are growing faster with more competition (Maravillo et al., 2019; Motalleb et al., 2018; Moye-Holz et al., 2019; Murto et al., 2019; Niu et al., 2012; OECD, 2017a, 2017b, 2017c). This has been confirmed by various empirical studies of industry and even of companies. This discovery not only concerns the Western economy, but also comes from research in Japan and South Korea, as well as from developing countries. The effects of increased competition often affect sectors, which are adjacent to those in fierce competition. First of all, strong competition in supplier sectors can "increase" productivity and employment in the consumer sectors and through the economy more broadly. This is largely due to competition that improves distribution efficiency by allowing more efficient firms to enter the market and gain market share at the expense of less efficient firms. Therefore, the laws or anti-competitive behavior preventing entry to the market and expansion may be particularly harmful for economic growth. Competition also improves firms' productivity, as companies facing competition appear to be better managed. It is even, can be applicable in sectors with important social and economic outcomes: for example, there is increasing evidence that competition in healthcare can improve quality results. There is also evidence that intervention to promote competition will increase innovation; firms facing competition innovate more than monopolies. The connection is not straightforward: it may be that on average, competitive markets have the most innovation, weaker innovation are showcasing both monopolies and highly competitive markets. However, since competition policy focuses on the introduction or enhancement of competition in poorly functioning markets rather than on moderately competitive markets, which would become hypercompetitive, it still means that most competition 
policies are designed to encourage innovation. Productivity increases due to more competitive markets. Because of increased competition in the market, the enforcement of competition law and the removal of barriers of competition, will result in faster economic growth (D'Aertrycke et al. 2017; Denis, 2012; Gissey et al., 2018; Hu et al., 2018; Lee et al., 2018; Lohmann \& Trischler 2017). The evidence base for deregulation of the product market is still stronger, with many deregulation cases leading to comparisons between industries and countries over time. In addition, regulatory policies specifically designed to foster competition - especially in online activities - have increased productivity.

Of course, there are other policy goals besides GDP growth, and the OECD has measured and considered these goals more rigorously, when policy is formulated (OECD, 2017a, 2017b, 2017c).

The effects of competition on inequality have been less studied and are often thought to be malicious because competition creates winners and losers. However, the restrictions of competition are damaging the majority of society and profits usually go to the minority. Because of restrictions on competition, increased prices or lower quality and choice, quite often the poorest part of society are the most vulnerable.

Similarly, when concerns arise due to loss of employment, due to increased productivity, it should be noted that redundancy on competition, often are and other forms of technical progress (D'Aertrycke et al. 2017; Denis, 2012; Gissey et al., 2018; Hu et al., 2018; Lee et al., 2018; Lohmann \& Trischler, 2017). In addition, it has been shown that restrictions of competition reduce output and employment and it is, therefore, essential to ensure investment in new and alternative forms of productive employment.

Increased competition and the opening up of markets to competition through a careful assessment of new or existing laws and regulations will contribute to economic growth, increased productivity and greater overall prosperity (Ritter et al., 2019; Willems \& De Corte, 2008; Yang et al., 2019). As we have seen, competition assessment is the process of evaluating government laws, regulations, and / or laws to (1) identify those who can unnecessarily obstructing competition and (2) redesigning the rules to avoid undue distortions of competition. In order to be effective to adapt this process to government operations and institutions, the following five issues need to be considered:

- Which policies deserve to be assessed for competition?
- When should competition assessment be carried out in the policy-making process?

- Who should be responsible for drafting and reviewing the competition assessment project?

- How can politicians who do not take responsibility for the quality of regulation or competition have incentives to make the right assessment?

- What resources do you need to evaluate competition?

It will further become clear that there is no simple formula for the institutional implementation of competition assessment. Depending on the differences, the expected solutions will vary substantially between jurisdictions, such as whether a federal system exists, staff strengths, and the political environment (Willems \& De Corte, 2008; Yang et al., 2019). Although the toolkit builds on existing experience in identifying feasible opportunities, they should not be considered exhaustive. As can be seen in OECD report (2017a), the toolkit was considered very beneficial while performing very different reviews - impact assessment integrated into regulatory impact assessment, optional assessment that may be beneficial to competition, as well as market and sector studies. The depth of competition assessment should be proportionate to the potential negative effects of the policy on competition. The competition checklist allows quickly to check policies, identify those potential factors that unduly influence competition for further evaluation. Mostly separate laws or other legislation does not have this potential and therefore does not require a comprehensive competition assessment. Competition assessment may be carried out in the context of the assessment of laws and regulations in the implementation of policies and rules and regulations. Some governments and independent public bodies (such as national competition authorities, audit courts, etc.) have decided to review subsidies or for state-owned enterprises granted preferential approach to competition. Not all jurisdictions value their own laws from the competition point of view, but it was those who were most successful in terms of competition.

Some governments have begun to look at competition by evaluating new and existing policies. This is the most effective way to improve substantially competitive environment, but this requires a great deal of political will. Other governments have implemented a competition assessment form, focused solely on new policies.

Assessing competition at national, regional and local levels is a sound economic basis (Moye- 
Holz et al., 2019; Murto et al., 2019; Niu et al., 2012; OECD, 2017a). Evaluation is important to any government policy that may unduly restrict competition. Policies that set such boundaries are sometimes set at national level, but can also be developed at regional or local level. For example, anticompetitive policies for taxi services are often set at local level and specialist regulation that is harmful to consumers is often implemented at regional level.

Some governments have begun to look at competition by evaluating new and existing policies (Yang et al., 2019). This is the most effective way to improve the competitive environment substantially, but it requires great political will. Other governments have implemented a competition appraisal form that focuses solely on new policies. Assessing competition at national, regional and local levels is a sound economic basis. Evaluation is important to any government policy that may unduly restrict competition. Policies that set such boundaries are sometimes set at national level, but can also be developed at regional or local level. For example, anti-competitive policies in taxi services are often set at local level, while regulation of specialists, that harms consumers, is often carried out at regional level.

But "frontline" policy makers do not take the competition assessment process seriously unless their work is reviewed by an outside party (D'Aertrycke et al., 2017; Denis, 2012; Gissey et al., 2018; Hu et al., 2018; Lee et al., 2018; Lohmann \& Trischler, 2017). Control may be exercised by supervisors, officers having knowledge of competition expertise, such as those held by competition authorities, in one of the two variants mentioned. In the United Kingdom, the Regulatory System Manager, the Better Regulation Executive (BRE), is responsible for overseeing the impact of new regulatory proposals. The regulations were evaluated according to the guidelines issued by the Business Department in 2015, March, had a positive impact on competition and amounted to net zero costs and are rapidly monitored during the impact assessment process. Policymakers also have the discretion to assess whether or not their proposal will adversely affect competition.

Departments can contact the Competition and Markets Authority (CMA) for advice if their proposals raise competition issues that require more detailed analysis (Lee et al., 2018; Lohmann \& Trischler, 2017). The CMA also has the power to make recommendations to ministers if they are concerned about the potential impact of legislative proposals on competition. An assessment that is broader and more comprehensive than the Competition Checklist usually requires market definition and competencies of competitive analysis. For this reason, some countries require their competition authorities to review any new laws and regulations that are expected to have an economic impact before adopting appropriate provisions. In Mexico, for example, the competition authority must review any new secondary legislation that may affect competition. In Korea, the competition authority is responsible for reviewing a selection of new regulations. In Hungary, the competition authority is required to comment on the new regulations.

Many other countries before the new regulations were adopted organize horizontal consultations (D'Aertrycke et al., 2017; Denis, 2012; Gissey et al., 2018; Hu et al., 2018). Such consultation works better when competition commentators can start the process early are not required to comment on the policy as a whole and may intervene when they believe a significant potential problem may arise.

The degree of independence of the review body is also important. For example, in Australia in 1995 a new body was created to oversee the national and state or territory laws of the National Competition Policy and review of other legislation. The National Competition Council was created as a separate and independent body to oversee the new regulations and acts outgoing from competition service. Some national competition authorities, such as the former Spanish Comisión Nacional de la Competencia, have reviewed grant schemes and have published annual reports on grants.

Involvement of a competition authority or other governmental authority in the competition assessment process should not impede any subsequent government legal action under the competition laws of that jurisdiction. Competition assessments by definition are predictions based and in real life predictions can show insufficient or excessive harm to competition.

\section{Assessing competition in a distorted market economy}

Review of competition assessment seeks to identify a policy option, which allows the policy maker to achieve the goal under consideration with the least possible distortion of competition. Sometimes the correct object may be the reviewed policy, but less restrictive alternatives may be used on other occasions (Phillips \& Menkhaus, 2010; Pinto \& Falcão-Reis, 2019; Ren \& Zhang, 2014). 
Thus, if the checklist reveals that the policy under scrutiny is likely to distort competition, then consideration should be given to use other less distortive means for the same purpose. This exercise implies the need to identify all strategies to achieve the goal, to evaluate each option competitive impact and choose the option that offers the greatest benefit. Next we shall give guidance on how to identify less restrictive alternatives to achieve the purpose in question.

In order to identify less restrictive alternatives to certain policies is an exercise for a specific fact that requires a good understanding of this policy and to have a great deal of competence in that area (Brooks \& Lesieutre, 2019; Cimon \& Garriott, 2019; Croutzet \& Lasserre, 2017; Hu et al., 2018; Lee et al., 2018; Lohmann \& Trischler, 2017; Maravillo et al., 2019; Motalleb et al., 2018; Moye-Holz et al., 2019; Niu et al., 2012; OECD, 2017a, 2017b, 2017c; Phillips \& Menkhaus, 2010; Pinto \& Falcão-Reis, 2019; Ren \& Zhang, 2014; Ritter et al., 2019; Willems \& De Corte, 2008; Yang et al., 2019):

1. Set a policy goal. The first step is to set a clear policy goal. If the policy is pursued to remove market failure together with mechanism is needed a clear one description of the market failure by which the policy intends to solve or reduce the intensity of the market failure. It is also important to understand the overall regulatory environment. The policy objective can sometimes be found in the regulation itself, in higher-level legislation, in legislative discussions or in complementarity legislation when it was accepted.

Many policies are not implemented because of market failures but for social or other reasons. If there are other policies in the sector that pursue the same goal, it is important to identify any relationships that may exist between them and the policies in question. This should be taken into account when developing alternatives. Often, anticompetitive policies have strong business and political interests. Currently companies operating in the industry may try to use the regulatory process to guard against increased competition. It is likely that such efforts may result in loss of profit when it is higher competition. Having in mind the importance of the interests of existing market players it is important to understand the cause why anticompetitive regulations exist.

In defining the objectives to be pursued by the Regulation, the crucial key to that solution is that they are not defined in some way, so that less restrictive methods are unnecessarily rejected in order to achieve the same main purpose. This can happen when the stated goals determine the approach that will be used to achieve the main goal, instead of permission to consider all options. For example, a pollutant such as sulfur dioxide may come from several sources. Policies aimed at reducing pollution by controlling emissions from each source can achieve the desired goal of reducing overall emissions, but at the same time can prevent approaches that allow the use of markets, compete, and more effectively achieve the underlying common goal.

2. Identification of the specific regulatory elements that create the competition problems. The next step is to determine the nature of the competition problems caused by the policy in question and whether they are necessary to achieve the objective. This can be done using checklist. It is also necessary to identify specific policy elements or provisions that raise competition concerns. The question is whether these elements or provisions are necessary to achieve the objective or whether they could be modified to reduce or eliminate their negative effects on competition. This process allows the creation of a set of alternatives that will help to achieve the same goal as the policy in question, but does not distort or less distort competition.

3. Technical competence. The possible alternatives may depend on the technical characteristics of the subject being regulated. The types of technical expertise required for the preparation of regulations will vary according to the regulation under consideration. Technical competence may lie with the ministry or government body overseeing the Regulation. Such expertise can sometimes be biased in favor of the current regulatory regime. Alternative technical expertise may be outside the ministry, for example, within the academic community or outside the country when it turns out that country experts are biased in one direction or another. Companies may have relevant expertise but, but may be biased in favor of the rules that they think protect them. Potential start-ups, which are difficult to start because of legislation, may be less biased in citing restrictions on competition than previously established companies. Possible conclusions can be usefully presented for technical experts and existing interest groups at an early stage before the recommendation is finally established, also it can be ensured that there is consultation on reform before the law is introduced. Evaluators may request comments not only in writing, but also in the meetings; face-to-face communication is often very productive. In order to obtain the most useful expert feedback, the assessors may hold a 
short seminar for experts on competition assessment and checklist. Sometimes experts will be able to impose restrictions on competition when it is difficult for non-experts to extract them from the relevant regulations.

4. Understand the broader regulatory environment. When considering alternatives, it is important to consider not only the regulation under consideration, but also the network of relevant regulations, including general regulations, which have an impact. to the market in question to create alternatives.

5. Understand the changed business or market environment. When evaluating the proposed regulation or proposing alternatives, it is important to consider how business conditions have changed since the last implementation of the policy. If market conditions change, any initial regulation could be reassessed. Consideration may be given to the need for a stricter regulation, as in the case of maintaining the current regulation. or repealing the regulation completely.

6. Methods of Alternative Development. The purpose of the review of competition assessment is to identify a policy option that achieves the objective under consideration with the least possible distortion of competition. If the checklist shows that the policy in question is likely to distort competition, it must be examined whether the same objective can be achieved in a less distortive manner. This includes identifying all other possible policy approaches aimed at achieving a less distortive objective and possible ways of redesigning the proposed measure in order to minimize its impact on competition while pursuing the policy objective. Identification of possible policy alternatives is a fact-based exercise that often requires a thorough understanding of the policy and extensive experience in the field.

Experience in other jurisdictions can sometimes be helpful in developing alternatives if the circumstances are comparable. Like that in consultation with stakeholders it can be made interesting proposals because they have a good knowledge of the sectors and what alternatives can and cannot be implemented. However, these examples illustrate less restrictive means that can be used in place of more stringent, in most cases.

\subsection{Making greater use of economic incentives. nor regulation of external influences}

External effects are the costs or benefits of the product in terms of the environment, economics, health, safety, etc. which are not reflected in its price or cost (Ritter et al., 2019; Willems \& De
Corte, 2008; Yang et al., 2019). Thus, it is unlikely that the buyer will properly assess the external impact. If a product or activity causes external expenditures, it will tend to be too much since all costs are not reflected in its cost or return in the market. If the product creates external advantages, usually it will not be supplied because all its benefits do not reflect its price or market return.

Regulating the quantity, price or characteristics of the products or activities producing the exterior is one possible way in an attempt to correct their external effects. An alternative approach is to use general economic incentives such as subsidies, taxes or fees to internalize the externalities of these products at their market price. This method, if possible and if not causing unjustified distortion between businesses can leverage competitive market forces to determine effective prices, quantities and product characteristics. The government can provide market solutions that did not exist before, for example by creating emission permits and allowing those rights to be traded.

\subsection{Consumer information and education re- quirements compared to the required product characteristics}

Consumer protection is often cited as a reason to set mandatory product characteristics (Maravillo et al., 2019). Sometimes it may be enough disclosure, for example such as fat labeling on products. Some consumers may be more risk averse and this is not always the role of government to prevent it, but government can provide consumers with useful information to make their individual decisions.

\subsection{Prohibition of direct sales to consumers compared to providing adequate information to consumers}

From door to door and direct sales to the consumer are common practices in many markets (Yang et al., 2019). However, their use, especially in newly unregulated markets, often gives rise to complaints or concerns that many consumers buy products based on misleading or inadequate doorto-door or end-to-end information. One way to solve these problems is to ban door-to-door or direct sales.

An alternative approach is to set door-to-door requirements or to direct sellers in order to provide consumers with the information they need to make the right product choices. Another possible alternative is to require contracts to include discount clauses that allow consumers to review their purchasing decisions. Maximum contract length or auto-renewal ban can protect vulnerable or unin- 
formed users. Such measures can help to maintain the beneficial aspects of door-to-door and direct sales, while ensuring that consumers are properly informed.

\subsection{Control of advertising content rather than advertising bans to prevent harmful advertising}

As an alternative to advertising bans, advertising content control can be a way to eliminate harmful aspects of advertising while allowing you to continue useful aspects of advertising (Niu et al., 2012). For example, advertising a product as a discounted price compared to a previous or recommended price can sometimes be misleading. An alternative prohibiting a price discount is that adhere to the rules to limit the promotion of artificial discounts (for example, a company raises the price of a product from $€ 20$ to $€ 40$, and on the next day returns a price of up to $€ 20$ and advertises a product with a $50 \%$ discount).

\subsection{Examination of complaints of unfair com- petitive conduct according to competition law and regulation}

Aggressive or innovative business practices often cause complaints due to unfair or inappropriate competition requiring remedial regulation (Brooks $\&$ Lesieutre, 2019). For example, price caps are often offered in order to protect vulnerable companies from too low competitors' prices. As an alternative to regulation, competition law provides a fundamentally effective framework for preventing business practices where it is likely to harm competition and consumers, while permitting such practices where they promote competition, innovation and consumer benefits.

For example, low-price strategies can only be predatory or raise serious competition concerns only in limited circumstances. Price caps, instead of preventing harmful business conduct, can deter consumers to benefit from low prices.

\subsection{Voluntary and mandatory product stand- ards and business codes}

Although mandatory standards require that all relevant products be compliant minimum performance, reliability or other standards, and voluntary standards, if possible, can be a way for suppliers to inform them that some of their products meet minimum standards while allowing them to continue to provide other products, which do not meet the standards where some consumers prefer such products (OECD, 2017a, 2017b, 2017c). Voluntary business codes may be a less restrictive means of addressing consumer-related market issues than regulation. Instead of requiring all businesses to adopt the same business standards and processes, voluntary codes can provide less informed or more interested consumers with information, enabling them to choose better suppliers.

The burden of legal oversight and filing requirements can be disproportionately difficult for small businesses and can therefore be closed or terminated, hindering small businesses to enter the market and possibly reduce competition. To ensure that these competitors can remain or become operational when they are otherwise effective may be less stringent supervision of regulation or appropriate filing requirements.

In a set of alternatives there should always be a "do nothing" option as a benchmark for examining alternatives. There may be many or few alternatives: it is not necessary to have many opportunities if all possible solutions are explored. There may also be cases where suitable alternatives cannot be found, since those parts of the policy which distort competition are essential to achieve the objective. But before reaching that conclusion, all possible alternatives must be carefully considered.

\section{Conclusions}

Regulations can influence the behavior of suppliers not only by altering their ability to compete in the negotiations, but also by changing the incentive to act as vigorous competitors. The main reasons why suppliers are less able to compete in negotiations are due to regulations that can facilitate coordination between them or reduce customer willingness, ability or incentive to switch to different suppliers. Other reasons include profit or market share thresholds that limit potential returns on competition. Cartel behavior may more easily result in self-regulation or co-regulation by increasing the share of suppliers' output and price information or by removing the industry or branch from competition law.

The effects of increased competition in negotiations often affect sectors adjacent to those in which is fierce competition. In particular, strong competition in upstream sectors can "increase" productivity and employment in the downstream sectors and more broadly in the economy. This is largely due to competition that improves distribution efficiency by allowing more efficient companies to enter and gain market share at the expense of less efficient firms. Therefore, laws or anticompetitive behavior to enter the market and expansion can be particularly damaging to economic growth. 
Competition also improves firms' productivity, as companies facing competition appear to be better managed.

In practice, most of the choices that are made are qualitative, that is are not based on quantitative comparisons of variants. Relevant quantitative comparison data are not always available and, even if available, may not be possible to analyze. It is possible that very important competitive effects are practically immeasurable. For example, changes in the conditions of competition may affect incentives to innovate and develop new products. However, it is extremely difficult to quantify increased or decreased impact of innovation. Qualitative analysis combines facts and reasoning to justify which choices are better.

Qualitative analysis of reform options is a form of critical thinking. The advantage of qualitative analysis is that it is widely understood, requires little data, is as fast as possible, and ultimately practical. At the same time, qualitative analysis does not determine the value of increasing competition, so one of the main pro-competitive arguments may be missed regulations.

Quantitative analysis involves careful and rigorous use of numbers to estimate advantages of certain options compared to others. Although quantitative analysis may require less comparison of solutions, the techniques used may require more technical skills than qualitative analysis, and of course some data must be available. For particularly important or contentious issues, whenever possible is preferred for the quantitative analysis. Quantitative analysis can, for example, provide estimates of the benefits of social reform, such as how much less consumers will pay for post-reform products or how many jobs will be created. Limitation of available data or comparison time will often limit the cases in which quantitative analysis can be performed. It may also be difficult or impossible to quantify the user value of product differentiation and enhanced service. Thus, while quantitative analysis may help to select pro-competitive options, it will often have to be rejected on the basis of qualitative evidence.

\section{References}

Borne, O., Korte, K., Perez, Y., Petit, M., \& Purkus, A. (2018). Barriers to entry in frequency-regulation services markets: Review of the status quo and options for improvements. Renewable and Sustainable Energy Reviews, 81(1), 605-614. https://doi.org/10.1016/j.rser.2017.08.052

Brooks, E., \& Lesieutre, B. (2019). A review of frequency regulation markets in three U.S.
ISO/RTOs. The Electricity Journal, 32(10). https://doi.org/10.1016/j.tej.2019.106668

Cimon, D., \& Garriott, C. (2019). Banking regulation and market making. Journal of Banking \& Finance, 109. https://doi.org/10.1016/j.jbankfin.2019.105653

Cogley, T., Easley, D., Sargent, T., Tsyrennikov, V. (2018). A case for incomplete markets. Journal of Economic Theory, 178, 191-221. https://doi.org/10.1016/j.jet.2018.09.004

Croutzet, A., \& Lasserre, P. (2017). Optimal completeness of property rights on renewable resources in the presence of market power. Resource and Energy Economics, 49, 16-32. https://doi.org/10.1016/j.reseneeco.2017.03.004

D’Aertrycke, G. M., Ehrenmann, A., \& Smeers, Y. (2017). Investment with incomplete markets for risk: The need for long-term contracts. Energy Policy, 105, 571-583. https://doi.org/10.1016/j.enpol.2017.01.029

Denis, D. K. (2012). Mandatory clawback provisions, information disclosure, and the regulation of securities markets. Journal of Accounting and Economics, 54(2-3), 197-200. https://doi.org/10.1016/j.jacceco.2012.07.002

Gissey, G., Dodds, P., \& Radcliffe, J. (2018). Market and regulatory barriers to electrical energy storage innovation. Renewable and Sustainable Energy Reviews, 82(1), 781-790. https://doi.org/10.1016/j.rser.2017.09.079

Hu, J., Harmsen, R., Crijns-Graus, W., Worrell, E., \& van den Broek, M. (2018). Identifying barriers to large-scale integration of variable renewable electricity into the electricity market: A literature review of market design. Renewable and Sustainable Energy Reviews, 81(2), 2181-2195. https://doi.org/10.1016/j.rser.2017.06.028

Lee, A., Loschelder, D., Schweinsberg, M., Mason, M., \& Galinsky, A. (2018). Too precise to pursue: How precise first offers create barriers-to-entry in negotiations and markets. Organizational Behavior and Human Decision Processes, 148, 87-100. https://doi.org/10.1016/j.obhdp.2018.03.001

Lohmann, G., \& Trischler, J. (2017). Licence to build, licence to charge? Market power, pricing and the financing of airport infrastructure development in Australia. Transport Policy, 59, 28-37. https://doi.org/10.1016/j.tranpol.2017.06.009

Maravillo, H., Camacho-Vallejo, J., Puerto, J., \& Labbé, M. (2019). A market regulation bilevel problem: A case study of the Mexican petrochemical industry. Omega (in Press). https://doi.org/10.1016/j.omega.2019.08.012

Motalleb, M., Annaswamy, A., \& Ghorbani, R. (2018). A real-time demand response market through a repeated incomplete-information game. Energy, 143, 424438. https://doi.org/10.1016/j.energy.2017.10.129 
Moye-Holz, D., van Dijk, J., Reijneveld, S., \& Hogerzeil, H. (2019). The impact of price negotiations on public procurement prices and access to 8 innovative cancer medicines in a middle-income country: the case of Mexico. Value in Health Regional Issues, 20, 129-135. https://doi.org/10.1016/j.vhri.2019.04.006

Murto, P., Jalas, M., Juntunen, J., \& Hyysalo, S. (2019). The difficult process of adopting a comprehensive energy retrofit in housing companies: Barriers posed by nascent markets and complicated calculability. Energy Policy, 132, 955-964. https://doi.org/10.1016/j.enpol.2019.06.062

Niu, Y., Dong, L., \& Chen, R. (2012). Market entry barriers in China. Journal of Business Research, 65(1), 68-76. https://doi.org/10.1016/j.jbusres.2011.01.018

OECD. (2017a). Competitions assessment toolkit, 1 (54 p.). www.oecd.org/competition/toolkit

OECD. (2017b). Competitions assessment toolkit, 2 (54 p.). www.oecd.org/competition/toolkit

OECD. (2017c). Competitions assessment toolkit, 3 (54 p.). www.oecd.org/competition/toolkit

Phillips, O., \& Menkhaus, D. (2010). The culture of private negotiation: Endogenous price anchors in simple bilateral bargaining experiments. Journal of
Economic Behavior \& Organization, 76(3), 705 715. https://doi.org/10.1016/j.jebo.2010.08.004

Pinto, T., \& Falcão-Reis, F. (2019). Strategic participation in competitive electricity markets: Internal versus sectorial data analysis. International Journal of Electrical Power \& Energy Systems, 108, 432-444. https://doi.org/10.1016/j.ijepes.2019.01.011

Ren, F., \& Zhang, M. (2014). A single issue negotiation model for agents bargaining in dynamic electronic markets. Decision Support Systems, 60, 55-67. https://doi.org/10.1016/j.dss.2013.05.020

Ritter, G., Walkinshaw, L., Quinn, E., Ickes, S., \& Johnson, D. (2019). An assessment of perceived barriers to farmers' market access. Journal of $\mathrm{Nu}$ trition Education and Behavior, 51(1), 48-56. https://doi.org/10.1016/j.jneb.2018.07.020

Willems, B., \& De Corte, E. (2008). Market power mitigation by regulating contract portfolio risk. Energy Policy, 36(10), 3787-3796. https://doi.org/10.1016/j.enpol.2008.07.008

Yang, X., Zhang, Z., \& Gao, X. (2019). Asian-barrier option pricing formulas of uncertain financial market, Chaos. Solitons \& Fractals, 123, 79-86. https://doi.org/10.1016/j.chaos.2019.03.037 